\title{
Dinâmicas Comerciais no Espaço Intra-Urbano Favelado: 0 Caso da Rocinha ${ }^{1}$
}

Robson de Oliveira Lopes

\section{Resumo}

As favelas do Rio de Janeiro abrigam uma imensa população de trabalhadores e incluem também um grande número de atividades econômicas desenvolvidas por empreendedores, constituído principalmente moradores locais, o principal objetivo desse trabalho é analisar o desenvolvimento das relações produtivas dentro do espaço intra-urbano favelado, utilizando como estudo de caso a Favela da Rocinha, está que é considerada a maior favela da América Latina.

Palavras chave: Favela; Rocinha; Economia; Espaço Urbano.

\section{Abstract}

The slums of Rio de Janeiro harbor a vast population of workers and also include a large number of economic activities undertaken by entrepreneurs, consisting mainly local residents, the main objective of this study is to analyze the development of productive relations within the intra-urban slums, as a case study using the slum of Rocinha, is what is considered the largest slum in Latin America.

Keywords : Slum; Rocinha; Economics; Urban Area

\section{Introdução}

A Rocinha está localizada na Zona sul da cidade do Rio de Janeiro, situando-se entre os Bairros da Gávea e de São Conrado, que são bairros constituídos por uma população de alto poder econômico e que compõe parte da elite da cidade, pertencendo à Área de Planejamento (AP-2), pertencente a XXVII região administrativa².

A Rocinha é delimitada na região sul de seu território, pela Auto-Estrada Lagoa-Barra (RJ-071), que separa de São Conrado a noroeste, na parte de 
cima do morro, está limitada pela mata do Parque Nacional da Tijuca e ao lado oposto, a nordeste pela Estrada da Gávea, que a separa e a conecta a Gávea.

Figura 1

\section{Posição da rocinha em relação bairros de São Conrado e Gávea}

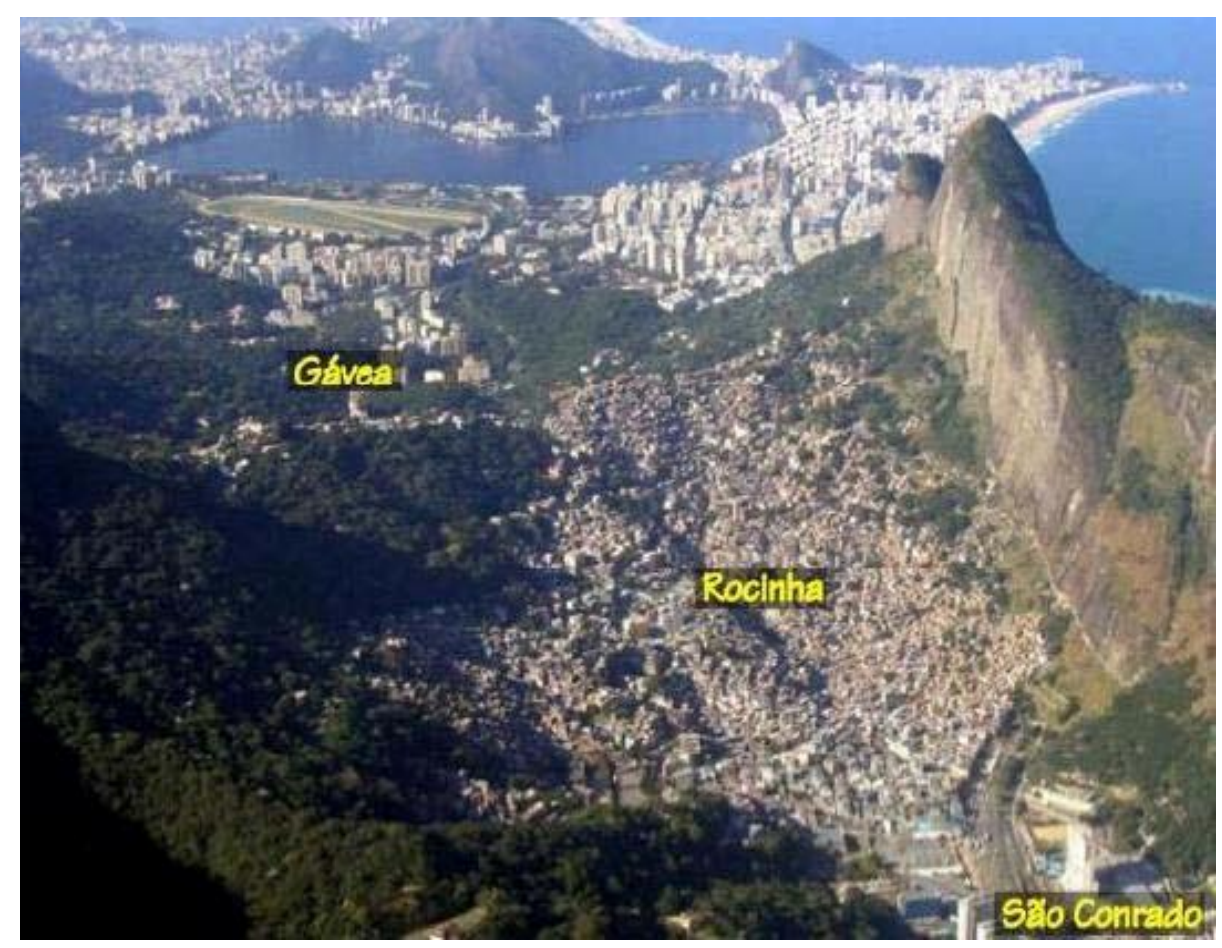

Fonte: KLINTOWITZ (2008)

Segundo o Censo /2000, IBGE, a Rocinha tem uma área territorial de 143,72 ha, onde $66,80 \%$ (96 ha) da área encontram-se acima da cota 100m, área que não é permitido construir por ser uma área de preservação ${ }^{3}$, os dados relativos ao total de moradores da Rocinha são muito contraditórios, pois, de acordo com o Censo do IBGE realizado em 2000, a população total da Rocinha seria de 56.338 habitantes, porém, um Censo realizado pela LIGHT em conjunto com as lideranças locais também em 2000, obteve como resultado aproximadamente 130.000 habitantes, um numero mais próximo da realidade do local segundo os governantes municipais. Entretanto, a Associação de moradores estipula um total de cerca de 200.000 habitantes na Rocinha, recentemente um censo sobre a comunidade realizada pelo Governo do Estado em 2008, contabilizou um total de 100.818 habitantes $^{4}$, assim fica muito difícil saber exatamente o número de moradores residentes nessa "cidade" chamada Rocinha. 
Uma das principais características evidenciadas na Rocinha nos dias atuais é o seu grande potencial comercial, uma quantidade expressiva e diversificada de comércios que confere ao lugar um caráter de auto-suficiência, onde segundo os moradores não é preciso ir buscar mercadorias em outros bairros, uma vez que os bens e serviços terceirizados oferecidos no local são suficientes para suprir o consumo da comunidade.

\section{Atividades comerciais na Rocinha}

Encontramos na paisagem interna um enorme número de estabelecimentos, identificando um desenvolvimento econômico integrado ao setor terciário de comércio e serviços, dentro do espaço intra-favela, há uma vasta diversidade dos tipos de comércio principalmente lojas de venda a varejo, bares, academias de ginástica, restaurantes, papelarias, entre outros, sendo a maioria micro e pequenas empresas, a existência delas atendem em grande parte no consumo diário dos moradores, sendo esses negócios responsáveis por uma numero considerável de empregos.

Aparentemente o comércio local apresenta uma resposta imediata à demanda dos moradores, não havendo projeções a respeito da possibilidade de criação de áreas comerciais que não estejam diretamente ligadas a grandes concentrações habitacionais. (ANDRADE, 2002:132)

Devido ao crescimento populacional, a Rocinha começou a dinamizar sua economia que primeiramente era constituída por comerciantes residentes, porém, a partir da década de 1990, com os investimentos de grandes empresas capitalistas dentro da comunidade, assim o local passou a ser um lugar de atração para grandes e médios empresários oriundos de fora da favela mostrando a favela hoje não apenas como local de moradia de uma população pobre, pois, existem diversos tipos de consumidores de um mercado com características de serviços em plena modernização para responder às demandas diversificadas de seus moradores.

$\mathrm{Na}$ Rocinha, podemos encontrar empresas consolidadas como, por exemplo, a rede de fast-food Bob's, a empresa de formação profissional Microlins, Rede de Drogarias Pacheco, agência dos Correios, a TV ROC, que viabiliza o sinal de tevê por assinatura para a comunidade, também encontramos três agências bancarias, sendo uma agencia estatal (Caixa 
Econômica Federal) e duas agencias privadas (Bradesco e Itaú), dessa maneira podemos observar em contraponto a instalação de empresas modernas de capital intensivo que Santos (1979) denomina como "circuito superior", que são responsáveis pela reprodução de padrão de consumo de nível similar à classe média dentro da favela.

Um outro indicador do dinamismo comercial e econômico da Rocinha aponta para as lojas de materiais de construção que são bastante requisitadas, já que o processo de verticalização das residências tem sido uma constante constituindo-se em uma das melhores oportunidades de negócio dentro da favela.

Conforme reportagem publicada pelo jornal "O Globo", mostrou que o número de estabelecimentos comerciais na Rocinha ao todo é de 6317, de acordo com as estatísticas realizadas, $37 \%$ das empresas são legalizadas e hoje o setor de negócios está atraindo um numero de aproximadamente 6000 pessoas que não moram na comunidade e trabalham na mesma, assim podemos verificar que a comunidade hoje em dia está atraindo investidores e mão-de-obra de outras localidades, de acordo com Leitão (2004), quando aborda sobre a dinâmica comercial na Rocinha, afirma: "que não passa um mês sem que um novo estabelecimento comercial abra suas portas".

Podemos analisar que a favela apresenta uma organização tipicamente capitalista, contando com grande vitalidade econômica, tendo uma diferenciação social bastante definida, criando uma "pequena burguesia favelada", nota-se uma desigualdade social dentro da localidade, conforme o evidenciado, pode-se delimitar uma estratificação do espaço social intra-favela, sobre a produção do espaço pode-se recorrer às palavras de Santos (1979):

A favela não reúne todos os pobres de uma cidade, e nem todos os que nela vivem podem ser definidos segundo os mesmo critérios de pobreza. Uma favela pode compreender tanto biscateiros, que vivem de rendas ocasionais, como assalariados dos serviços e das indústrias e mesmo pequenos empresários. (SANTOS, 1979:75)

A principal via de acesso à Rocinha é a Estrada da Gávea, esta atravessa toda a extensão da favela conectando os Bairros de São Conrado e Gávea, sendo uma característica atípica nas favelas cariocas, ao longo dessa estrada encontramos diversas conexões com vias secundárias, como a Via Ápia, Caminho dos Boiadeiros, Rua Dois, Rua Um, Ladeira da Cachopa, Subida do Laboriaux, entre outras de menor porte, assim como ligações entre becos internos na favela. 
O uso comercial se concentra em toda a extensão da estrada da Gávea, constituindo uma espécie de corredor comercial, que geralmente se localiza no andar térreo das edificações, além de diversos órgãos institucionais que atuam na comunidade, ao longo da via, pode-se perceber que os comércios se espalham ao decorrer das bifurcações das vias secundárias.

\section{Figura 2 - Distribuição de usos do solo em um trecho da Rocinha}

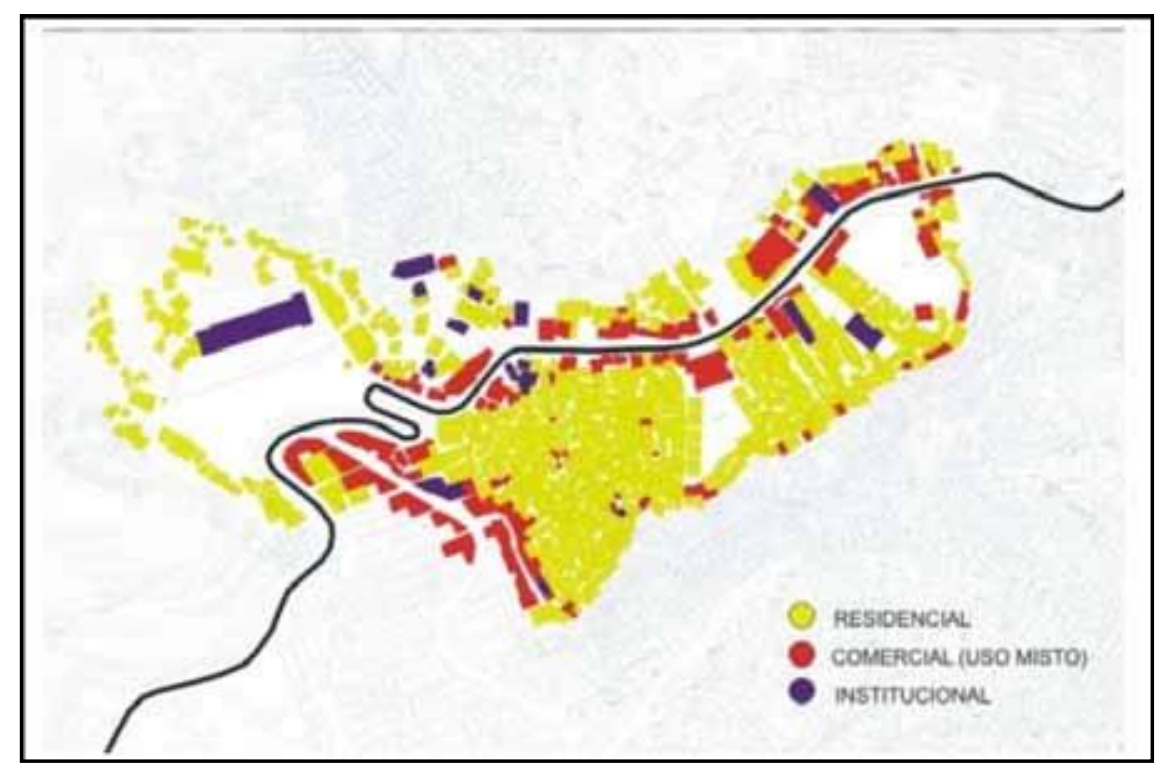

Fonte: MAYERHOFER \& TOLEDO, apud KLINTOWITZ (2008).

Nas áreas do Bairro Barcelos e Largo dos boiadeiros, encontramos o principal pólo dinâmico de comércio e serviços da favela, apresentando usos residenciais, assim encontramos usos mistos desse espaço, principalmente pela quantidade de fluxo de pessoas que passam por essas áreas, pois, a proximidade da Auto Estrada Lagoa-Barra, dá maior mobilidade de fluxos, devido ao grande número de linhas de ônibus que circulam para diversas áreas da cidade passam neste local. 
Figura 3 - Via Ápia

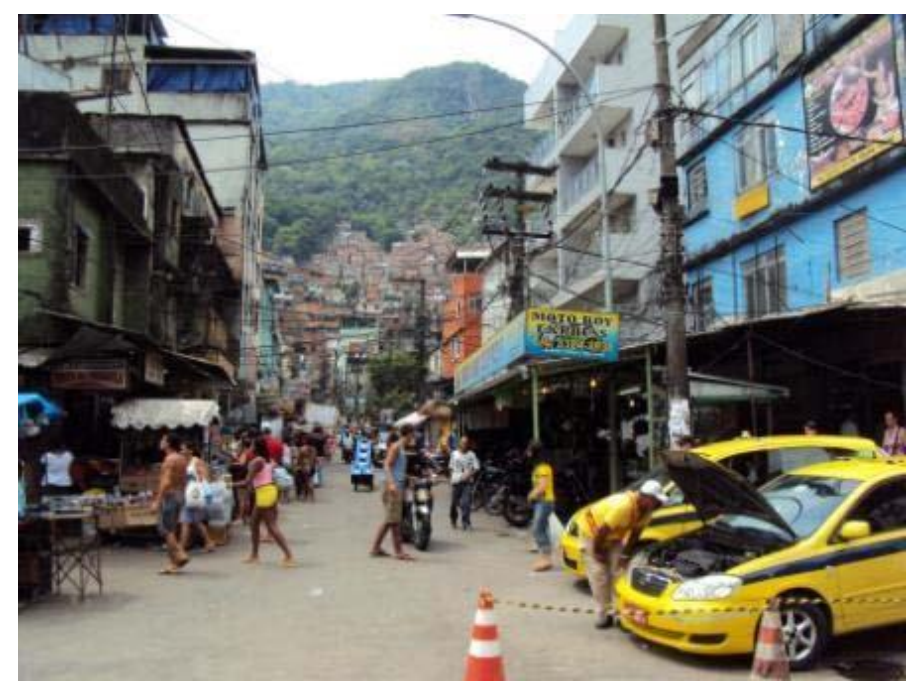

Fonte: (Lopes, 2010)
Figura 4 - Largo dos Boiadeiros

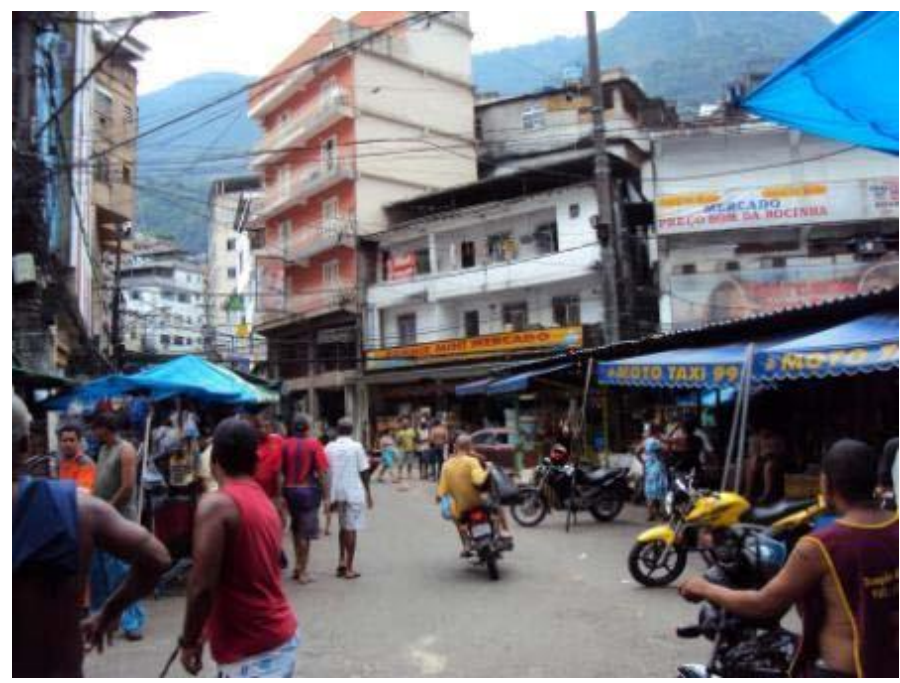

Fonte: (Lopes, 2010).

As empresas principais que atuam no setor formal da economia estão localizadas nas áreas de intensa circulação, misturadas com um grande número de pequenos empresários informais ou trabalhadores por conta própria que estão dispersos por toda a Rocinha sejam em pontos fixos de mercados através de lojas, seja como camelôs.

O comércio local também apresenta vitalidade surpreendente. Ao Longo da Estrada da Gávea encontramos, com maior ou menor concentração, diversos bares, lojas de materiais de construção, pequenas mercearias, farmácias, lojas lotéricas e salões de beleza. O Largo dos Boiadeiros e o Bairro Barcelos, na parte baixa da Rocinha (...) são áreas nitidamente comerciais ali foram instaladas, agencias bancárias, lojas de celular, além de uma gama diversificada de lojas, venda de serviços e produtos como cursos, academias, lojas de roupas, utensílios domésticos e moveis aviários, consultórios médico policlínica da Rocinha -, além dos muitos bares e lanchonetes. (ANDRADE, 2002:84)

Sobre o comércio ambulante (Camelôs), esses trabalham dispersos pela comunidade, que se localizam principalmente nas ruas que atendem a grande fluxo de pessoas Via Apia e Largo dos Boiadeiros e na entrada da Favela, num trecho de conexão entre a Rocinha e São Conrado, o Governo delimitou uma respectiva área para instalação de um mercado popular ${ }^{6}$, que possui cerca de 160 comerciantes informais. 
Figura 5 - Camelódromo

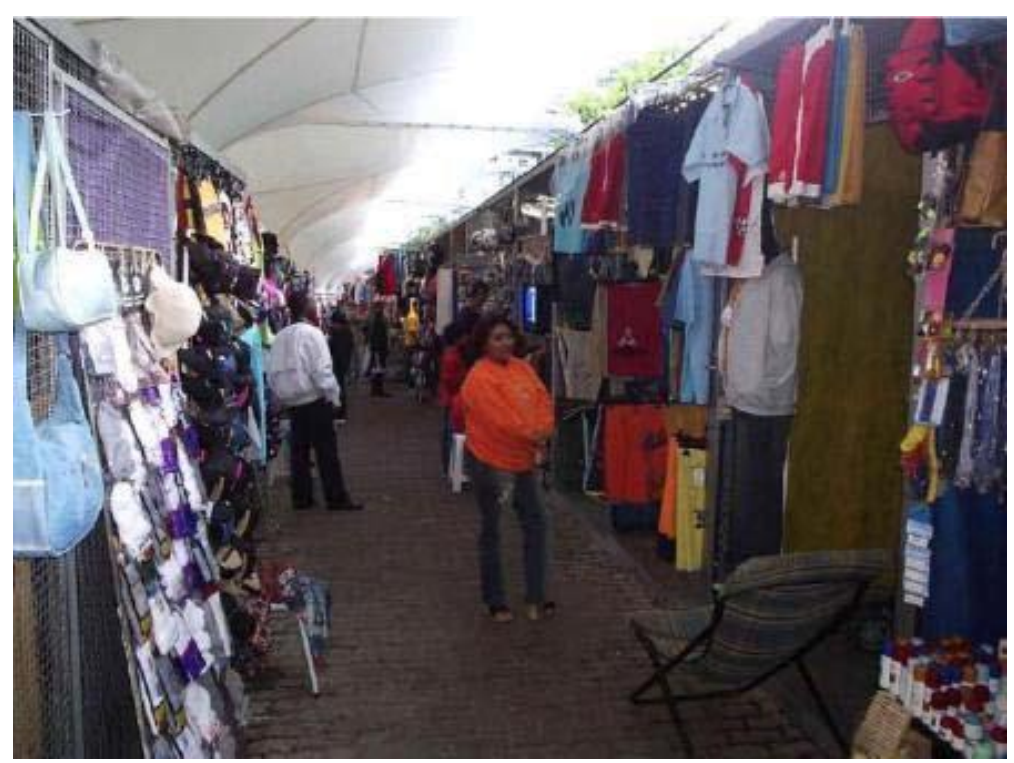

Fonte: CARMO (2005)

Em outras localidades da Rocinha encontramos um comércio menos desenvolvido a não ser na entrada para a Rua1, pois esse local é uma área de intensa circulação de moradores, tendo um intenso fluxo de pedestres por ser área acesso a muitos locais internos na favela principalmente para os moradores que residem na parte mais alta da Rocinha.

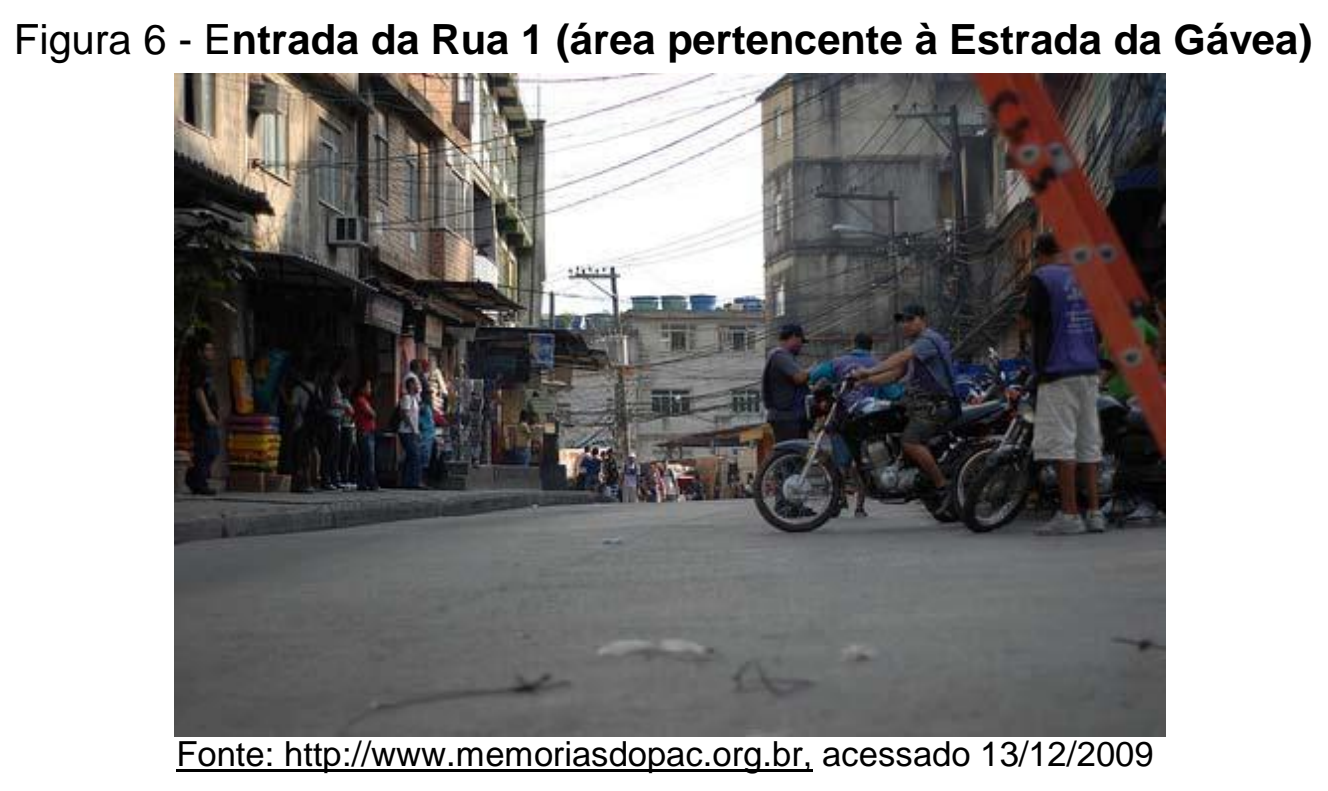

Na parte interna da rocinha os comércios encontrados são constituídos por pequenas empresas informais, que se mantém principalmente para 
manutenção e compra de utensílios de necessidades básicas do dia-dia, no interior de becos ${ }^{7}$ espremidos e estreitos que dificultam a circulação de pessoas.

Nesses locais um tipo de comércio comum são as biroscas, que são pequenos pontos de venda de bebidas e outros itens de primeira necessidade que estão espalhados por toda a comunidade, tendo uma função primordial, pois, são pontos de referencia de localização de determinadas moradias e funcionando muitas vezes como ponto de encontro ou de estar dos moradores, já que não encontramos no interior da Rocinha espaços públicos dedicados ao lazer, dessa maneira esses comércios acabam sendo um ponto de lazer e encontro durante os horários de folga dos trabalhadores.

Podemos sintetizar que a Rocinha formou-se um espaço multifuncional, com espaços híbridos dotados de funções e vivências múltiplas e em constante mutação, dentre esses espaços, muitos estão se transformando de acordo com o tempo sem ficarem inertes, assim, caracterizando uma vitalidade de funções e apropriações do espaço dentro da comunidade.

\section{Considerações Finais}

No decorrer desse trabalho foram mostradas diversas questões, buscando fazer uma discussão sobre as relações de produção no espaço urbano, referindo-se as estratégias de sobrevivências das populações segregadas sócio-espacialmente.

Foi observada a produção do espaço-Favela, enfatizando as questões relacionadas ao seu espaço interno, levando em consideração o crescimento exponencial da atividade comercial na comunidade, apesar de a favela ser caracterizada por referências no senso comum pelas carências e ausências, na Rocinha evidencia-se uma estrutura interna complexa e hierarquizada do seu espaço, mostrando uma heterogeneidade espacial e dinâmicas econômicas similares a "cidade formal".

A intensa densidade populacional levou a proliferação de uma economia estável e dinâmica, que tornou a Rocinha é um pólo de atração de grandes e médias empresas consolidadas no mercado formal, hoje oficialmente transformado em bairro, vê-se que a Rocinha não perdeu o estigma de maior favela da América Latina. 
Notas

1- O artigo escrito foi adaptado de parte do trabalho de conclusão de curso apresentado na Uerj-FFP, sobre orientação do Prof. Dr. Andrelino de Oliveira Campos.

2- O município do Rio de Janeiro é dividido em 05 áreas de planejamento (AP), que são subdivididos em 34 Regiões Administrativas. (IPP-2005)

3- "O Decreto numero 322 de 1976, que aprovou o Regulamento de Zoneamento do Município do Rio de Janeiro, no cap.IX, Seção 1, que trata da Zona Especial ZE-1, vem limitar a ocupação nas áreas do Parque Nacional da Tijuca, considerando non aedificandi as áreas que estão acima da curva de nível de 100m. Com base neste decreto, após a sua publicação, fica proibida qualquer construção acima da cota 100m." (FRANCISCO apud KLINTOWITZ, 2008).

4- Fonte:

http://odia.terra.com.br/portal/rio/html/2009/7/numeros do censo da rocinha i mpressionam 24005.html, acessado em 23/09/2009.

5- COSTA, Jacqueline \& DAFLON, Rogério. A explosão demográfica da Rocinha. $O$ Globo, Rio de Janeiro, 25 de Março de 2009. Rio, p.11.

6- Também conhecido como camelódromo da Rocinha.

7- Os becos são espaços estreitos, com traçado irregular, que em muitos casos permitem apenas a circulação de uma pessoa por vez (...) o beco na favela não é necessariamente sem saída. (ANDRADE, 2002:91).

\section{Bibliografia}

ABRAMO, Pedro. Mercado para imóveis de uso comercial em favelas: estudo piloto no Jacarezinho In: Coleção Estudos Cariocas. IPP-RJ, Julho, 2003.

ANDRADE, Luciana da Silva. Espaço Público e Favelas: Uma Análise da Dimensão Publica dos Espaços Coletivos Não Edificados da Rocinha. Tese de Doutorado - UFRJ/Instituto de Geociências, Rio de Janeiro, 2002. 
CARMO, Marcio Lima do. O microcrédito como tentativa de democratização do acesso ao crédito, no contexto da economia popular e solidária: um estudo de quadro comparativo com Vivacred/Rocinha. Dissertação de mestrado. IPPUR. RJ. 2005

CAMPOS, Andrelino. Do Quilombo à Favela: a produção do "espaço criminalizado no Rio de Janeiro". Rio de Janeiro: Bertrand Brasil, 2005.

CARMO, Marcio Lima do. O microcrédito como tentativa de democratização do acesso ao crédito, no contexto da economia popular e solidária: um estudo de quadro comparativo com Vivacred/Rocinha. Dissertação de mestrado. IPPUR. RJ. 2005

CORRÊA, Roberto Lobato. O espaço urbano. São Paulo: Ática, 1989.

KLINTOWITZ. Danielle Cavalcanti. A (re) invenção da praça. A experiência da Rocinha e suas fronteiras. Dissertação de Mestrado. PUC/Campinas. SP, 2008

LEITÃO, Gerônimo. Dos Barracos de madeira aos prédios de quitinete: uma analise do processo de produção da moradia na favela da rocinha ao longo de cinqüenta anos. Tese de Doutorado. Rio de Janeiro. UFRJ, 2004

LOPES, Robson de Oliveira. Economia informal e o processo de verticalização das moradias na Favela da Rocinha. Monografia apresentada na Universidade do Estado do Rio de Janeiro, Faculdade de Formação de Professores, 2010.

SANTOS, Milton. O Espaço Dividido. Os Dois Circuitos da Economia Urbana dos Países Subdesenvolvidos. São Paulo: São Paulo, Francisco Alves Editora S.A, 1979.

SOUZA, M.L. ABC do desenvolvimento urbano - 3르. - Rio de Janeiro: Bertrand Brasil, 2007.

VALLADARES, Licia do Prado. A invenção da favela: do mito de origem a favela.com. Rio de Janeiro: Ed. FGV, 2005. 
REVISTA TAMOIOS

Sites

http://www.rocinha.org/

http://odia.terra.com.br/portal/rio/html/2009/7/numeros do censo da rocinha i mpressionam 24005.html

TAMOIOS. ANO V. № 2, 2009 - ISSN 1980-4490 